\title{
Dental core training for the future GDP: is it worth it?
}

\author{
Ali Al Hassan, ${ }^{*}$ Syed Nazar²
}

\begin{tabular}{l|l|l|l} 
Key points & \multicolumn{2}{l}{} & \\
\hline $\begin{array}{l}\text { Provides understanding of the } \\
\text { benefits and shortfalls of dental core } \\
\text { training. }\end{array}$ & $\begin{array}{l}\text { Discusses consideration points for } \\
\text { dental core training application. }\end{array}$ & $\begin{array}{l}\text { Compares and contrasts the relative } \\
\text { benefits and shortfalls of dental core } \\
\text { training for the future GDP. }\end{array}$ & $\begin{array}{l}\text { Provides a reflection on how dental } \\
\text { core training skills can be transferred } \\
\text { to general practice. }\end{array}$ \\
\hline
\end{tabular}

\begin{abstract}
In this article I highlight the benefits and shortfalls of the dental core trainee year for one who has no interest in specialising and sees their eventual future as a general dental practitioner (GDP). I conclude that the dental core trainee year has great advantages and adds value to the future GDP.
\end{abstract}

\section{Introduction}

Coming to the end of dental foundation training (DFT) I had a decision to make: to go straight into general dental practice or to take a year aside as a dental core trainee, specifically in oral and maxillofacial surgery (OMFS). I knew where I wanted to be in 20 years' time - general cosmetic dentistry and implantology. I ended up choosing dental core training (DCT) and in this article I aim to highlight the benefits and shortfalls of the dental core trainee year for one who has no interest in specialising, at least to begin with, and sees their eventual future as a general dental practitioner (GDP). Was DCT a wasted year spent learning pointless, nontransferable skills with no relevance for the future GDP aside from a deskilling exercise? Or did it offer valuable, tangible skills and much needed confidence for one to practise in the general environment with more knowledge, expertise and decisiveness.

'Clyde House Dental Practice, 42 Bath Road, Swindon, Wiltshire SN1 4AY; ${ }^{2}$ OMFS Royal Derby Hospital, Derby, Derbyshire, DE22 3NE

Correspondence to: Ali Al Hassan

Email: alhassan01@gmail.com

Refereed Paper.

Accepted 21 December 2018

DOI:10.1038/s41415-019-0092-2

\section{Things to consider before DCT}

The decision to apply for DCT is a big one. I was torn between undertaking DCT for a year or two and beginning work as an associate GDP. In situations like these I have always found it useful to discuss my goals and pathways with others, rather than wrestling with the decision alone. Ironically, it turned out that people I highly respected advocated going both ways, leaving me with indecision. Seeking advice from respected colleagues and mentors, however, meant that I was much more informed about the long-term implications of this decision, either way. I finally decided to apply for DCT using loss aversion thinking. My thinking was that the potential loss from missing out on DCT would be more impactful on my career than the potential temporary loss from deskilling, with a handpiece and in other areas of general dentistry not encompassed in my DCT post for the year.

Following this I made a strict plan of what I wanted. For me this was:

1. An oral and maxillofacial surgery or oral surgery (OS) post, as I wanted to improve my surgical skills, supplementing the relatively little experience I had received previously from dental school and DFT

2. My own dedicated OS list, as I had heard some posts didn't let the DCTs actually get much hands-on surgical experience
3. A secondary area of training in something new within the post, such as implants or sedation.

Following my research, I only ranked those posts which fitted my plan, and in this way, whatever happened next would be positive. Either I would get a DCT post which would hit my development needs, or if I didn't get a place I would go into general practice and not have to worry about the whole DCT deskilling aspect anyway. In this case I could still use separate courses to upskill.

To summarise, for someone thinking about DCT I would recommend:

1. Asking for advice

2. Planning needs and being strict with them when ranking

3. Making sure the DCT post selected would have tangible benefits for the rest of one's career, to make up for the loss of handpiece experience and break in other areas, for example I knew the soft tissue skills and exodontia experience would directly translate to practice and future implant training.

\section{Was DCT a setback or an enhancement?}

Doing DCT has obvious disadvantages. Focusing on arguably one area so soon after graduation meant that the transition back to practice was slow to begin with. Firstly, I 
had to go over some of my general theory. Thankfully I completed my MFDS part 2 in the middle of the year which made me go through much general theory anyway, which meant I just needed a quick brush up on the relevant areas of dentistry I had not been practising for the year. Also, when beginning DCT I thought that I would lose some skills I had been developing beforehand, such as composite manipulation and handpiece control among other things. It turned out that these things came back like riding a bike; I was surpassing my previous DFT work relatively quickly. In reality the hardest task was simply getting familiar again with the NHS rules and regulations in relation to general dentistry. Another issue that had been mentioned to me was that sometimes it could be difficult getting a job straight out of DCT especially in OMFS, with practices worried that I wouldn't be an efficient GDP right from the off. In reality this wasn't a problem at all with current demand for associates being as high as ever - I had no problem getting a job which was right for me. The only other disadvantage was that I as a DCT had a much lower remuneration than my peers who had gone straight into general practice, although this was not something I was worried about.

On the other hand, the advantages of DCT were vast - I felt much more confident in managing and communicating with patients who had complex medical histories after being routinely exposed to them in secondary care. My surgical skills were greatly improved following this post. Prior to DCT I had only completed a handful of surgical procedures under supervision, and post DCT I felt much more confident handling surgical treatments independently as well as manipulating soft tissues. I was much better at delivering minimal pain anaesthesia and of course, exodontia. Aside from this I completed the theory and practical cases to become an independent sedation practitioner. All of this made me a well-rounded professional with many more treatment options I could offer to my patients and a greatly enhanced CV. In the future I want to develop my skills in cosmetic dentistry and implants, both areas for which the skills I learnt in DCT would be invaluable.

\section{Conclusion}

Overall, the disadvantages of DCT paled in comparison to the advantages. All of the issues to do with deskilling were gone within the first three months of work as a GDP, with the enhanced knowledge and skills of DCT lasting indefinitely. Furthermore, one year of extra training means nothing over a life long career with the comparative benefits being profound. As long as DCT is well researched, planned and thought out with a long-term vision of development in mind, it can be a year that adds tremendous value to the future general dental practitioner. As a final thought, if you didn't plan on specialising before, at least post DCT you would be more certain. 